\title{
1 To the canopy and beyond: Air samples 2 reveal wind dispersal as a driver of ubiquitous protistan pathogen assembly in tree canopies
}

Robin-Tobias Jauss ${ }^{a \#[c o]}$ \& Anne Nowack ${ }^{a[c o]}$, Susanne Walden ${ }^{b}$, Ronny Wolfa, Stefan Schaffer ${ }^{a}$, Barbara Schellbach ${ }^{c}$, Michael Bonkowski ${ }^{b}$, Martin Schlegel ${ }^{a}$ d\#

a University of Leipzig, Institute of Biology, Molecular Evolution \& Animal Systematics,

8 Talstraße 33, 04103 Leipzig

9 b University of Cologne, Institute of Zoology, Terrestrial Ecology, Zülpicher Straße

10 47b, 50674 Köln

$11{ }^{\mathrm{c}}$ Max Planck Institute for Evolutionary Anthropology, Department of Evolutionary

12 Genetics, Deutscher Platz 6, 04103 Leipzig

$13{ }^{d}$ German Centre for Integrative Biodiversity Research (iDiv) Halle Je na Leipzig,

14 Deutscher Platz 5e, 04103 Leipzig

$15{ }^{\left[c_{0}\right]}$ These authors contributed equally and should be considered joint first author.

16 Author order was determined in order of decreasing seniority

17 \# To whom correspondence should be addressed: jauss@uni-leipzig.de,

18 schlegel@uni-leipzig.de

19 Keywords: Airborne Microorganisms, Protists, Forest Ecosystems, Canopies,

Pathogens

\section{Abstract}

We analyzed air dispersal of the protistan phyla Cercozoa and Oomycota with an air sampler near the ground $(\sim 2 \mathrm{~m})$ and in tree crowns $(\sim 25 \mathrm{~m})$ of three tree species (oak, linden and ash) in a temperate floodplain forest in March (before leafing) and May (after leaf unfolding) with a cultivation-independent high throughput metabarcoding approach. Both, Cercozoa and Oomycota, contain important pathogens of forest trees and other vegetation. We found a high diversity of Cercozoa and Oomycota in air samples with 122 and 81 OTUs, respectively. Especially oomycetes showed a high temporal variation in beta diversity between both sampling dates. Differences in community composition between air samples 
30 in tree canopies and close to the ground were however negligible, and also tree species

31 identity did not affect communities in air samples, indicating that the distribution of protistan propagules through the air was not spatially restricted in the forest ecosystem. OTUs of plant pathogens, whose host species that did not occur in the forest, demonstrate wind dispersal of propagules from outside the forest biome. Overall, our results lead to a better understanding of the stochastic processes of wind dispersal of protists and protistan pathogens, a prerequisite to understand the mechanisms of their community assembly in forest ecosystems.

\section{Importance}

39 Wind dispersal has been shown to play a crucial role in protistan community assembly. The 40 protistan taxa Cercozoa and Oomycota contain important plant parasites with a major ecologic and economic impact. However, comprehensive assessments of cercozoan and oomycete diversity in forest air samples were lacking. Using a cultivation-independent high throughput metabarcoding approach, we analyzed cercozoan and oomycete air dispersal in forest floors and the canopy region - a potential filter for microbial propagules. Our study provides insights into the diversity and community assembly of protists within the air, contributing to a better understanding which factors drive the distribution of plant pathogens within forest ecosystems.

\section{Introduction}

49 The air is an effective means of long-distance propagation for a wide range of microbial organisms (Foissner \& Hawksworth, 2009; Pepper \& Dowd, 2009). The phyllosphere - and

51 especially the crowns of trees - are the largest biological interface between the soil and the 52 atmosphere (Ozanne et al., 2003; Ellwood \& Foster, 2004), which therefore may act as a 53 huge natural filter for airborne microbial propagules, including unicellular Eukaryotes

54 (Protists). Within the paraphyletic taxon of protists, the group of Cercozoa (Rhizaria) are highly diverse in morphology and physiology and show a high functional and ecological 
variety (Bass et al., 2009; Harder et al., 2016). They dominate terrestrial habitats (Urich et al., 2008; Voss et al., 2019) and harbor important plant pathogens, such as the Endomyxa, which have recently been elevated from the Cercozoa into a separate phylum (CavalierSmith et al., 2018). Another protistan taxon, the Oomycetes (Stramenopiles), contain important parasites of forest trees, and many lineages produce caducous sporangia for dissemination (Goheen \& Frankel, 2009; Robideau et al., 2011; Lang-Yona et al., 2018). With almost 800 described species, Oomycota are reported to have a broad distribution and a wide variety of ecological roles (Robideau et al., 2011; Thines, 2014; Judelson, 2017). Further, it is one of the eukaryotic groups with a great impact on ecosystems, as well as on economics and human health: the most famous species is Phytophthora infestans, which causes the potato blight. In the 1840s it led to the great famine in Ireland followed by massive emigration (Lara \& Belbahri, 2011; Robideau et al., 2011).

Protists can be passively disseminated over long distances by viable propagules, mostly as resting stages (cysts), while some groups, especially pathogens with more complex life cycles, also form sporangia for dispersal (Cowling, 1994; Kageyama \& Asano, 2009). Cysts are formed under unfavorable conditions, e.g. due to dryness, lack of food, or microbial antibiotics (Petz \& Foissner, 1988; Adl \& Gupta, 2006; Jousset et al., 2006), and it has been assumed that the cyst bank plays an important role for the resilience of protists and their functions in terrestrial environments (Geisen et al., 2017). Viable protist cysts can be retrieved from soils even after decades (Moon-van der Staay et al., 2006; Kageyama \& Asano, 2009), leading to the long-standing question of how cosmopolitan protists are (Finlay, 2002; Fenchel \& Finlay, 2004; Foissner, 2009).

Finlay et al. (2001) proposed that the spatial distribution of protistan propagules is influenced by several randomizing factors, such as soil particles dispersed by wind, convective transport, percolating rainwater, fog or animals. Rogerson and Detwiler (1999) determined that on average 0.25 cysts $\mathrm{m}^{-3}$ are contained in the air depending on wind speed 
and time since last precipitation. Using a molecular approach, Genitsaris et al. (2014) came to generally similar conclusions, while they further detected operational taxonomic units (OTUs) with constant presence as well as OTUs exhibiting seasonal variation. High humidity increases the chance of survival of transported microbes and promotes their deposition (Fuzzi et al., 1997; Evans et al., 2019) and airborne microorganisms can be transported in fog droplets by atmospheric turbulence over long distances (Fuzzi et al., 1997; Amato et al., 2005).

Recently, Jauss et al. (2020) confirmed a ubiquitous distribution of Cercozoa and Oomycota in a floodplain forest, despite strong differences in community composition of different microhabitats related to differences in the relative abundance of taxa. This led to the conclusion that within forest ecosystems both cercozoans and oomycetes can colonize most habitats, in which they then however do not perform similarly well due to habitat filtering. One reason for this ubiquitous presence of these protists could be wind dispersal.

Here, we studied the air dispersal of Cercozoa, Endomyxa and Oomycota by a cultivationindependent high throughput metabarcoding approach to analyze protistan diversity in the air surrounding tree canopies and near the ground of a temperate floodplain forest, to gain a deeper insight into the mechanisms how protists and their pathogenic lineages are distributed in the environment. These examinations tackled three hypotheses: (1) Wind dispersal explains the ubiquitous presence of these protists in the floodplain forest. (2) There are differences in the distribution in the vertical plane as a strong discrepancy between canopy and ground habitats was previously described. (3) Temporal variation of wind dispersed propagules further drives the community and pathogen assembly in forest ecosystems. 


\section{Material and Methods}

\subsection{Sampling and DNA extraction}

Air samples were taken in a temperate deciduous floodplain forest in the northwest of the city of Leipzig, Germany (51.3657 N, 12.3094 E) with a MicroBio MB2 Bioaerosol Sampler (Cantium Scientific, Dartford, UK) containing 1\% agar plates. The samples were collected under defined conditions drawing $100 \mathrm{l} / \mathrm{min}$ of air for ten minutes in two strata: (1) near the ground $(\sim 2 \mathrm{~m})$ and (2) in $\sim 25 \mathrm{~m}$ height in tree canopies with the help of the Leipzig Canopy Crane (LCC) facility. Two samplings were carried out - one in March and one in May 2019. For each sampling, three tree species with three replicates each were chosen (Quercus robur, Tilia cordata and Fraxinus excelsior). As non-arboral control, samples were also taken on the crane tracks near the ground and at canopy height. Two plates per stratum and of each replicated tree species were collected, yielding 40 plates per sampling. After air sampling, the agar plates were taken out of the instrument, sealed with parafilm to prevent contaminations and frozen until the DNA was extracted with the DNeasy PowerSoil ${ }^{\circledR}$ Kit according to the instructions supplied by the manufacturer. Weather conditions were tracked with a WebVIS data logger attached to the crane (Umweltanalytische Produkte $\mathrm{GmbH}$, Ibbenbüren, Germany) (Table 1).

Table 1: Weather conditions at the sampling days in March and May 2019.

$$
\text { March May }
$$

Average temperature $\left[{ }^{\circ} \mathrm{C}\right]$

Average humidity [\%]

Average wind speed $[\mathrm{m} / \mathrm{s}]$

Last precipitation event
6.5

14.3

59.4

75.0

4.01

Immediately before sampling 


\subsection{PCR amplification and sequencing}

124 DNA was amplified in duplicates with tagged oomycete- and cercozoan-specific primers

125 (Fiore-Donno \& Bonkowski, 2020; Jauss et al., 2020; Fiore-Donno et al., 2020)

126 (Supplementary Tables 1-2). PCR-products were purified following the directions of the

127 NucleoSpin ${ }^{\circledR}$ PCR clean-up protocol. Afterwards, DNA concentrations were measured with

128 the Qubit ${ }^{\mathrm{TM}} 4$ fluorometer in combination with the Qubit ${ }^{\mathrm{TM}}$ dsDNA HS Assay Kit. For

129 consecutive Illumina MiSeq Sequencing, a library was prepared following the Meyer and

130 Kircher (2010) protocol. DNA concentrations were checked repeatedly before and after

131 Illumina sequencing by utilization of DNA chips analyzed with the Agilent 2100 Bioanalyzer.

132 Between the steps of library preparation, reaction clean-up was performed with the AMPure 133 XP System using carboxyl coated magnetic beads (SPRI beads). Subsequent steps and the

134 Illumina MiSeq sequencing itself were performed by the sequencing team of the Max Planck

135 Institute for Evolutionary Anthropology in Leipzig, Germany.

2.3. Sequence processing and statistical analyses

137 Bioinformatic and statistical analyses followed the pipeline described in Jauss et al. (2020).

138 Briefly, resulting reads were merged and clustered into operational taxonomic units (OTUs) 139 using a custom pipeline utilizing cutadapt v1.18 (Martin, 2011), Swarm v2.2.2 (Mahé et al., 140 2015) and VSEARCH v2.10.3 (Rognes et al., 2016). OTUs were then annotated using 141 NCBl's non-redundant nucleotide database and the Protist Ribosomal Reference Database 142 (Guillou et al., 2013) for oomycete and cercozoan OTUs, respectively (Supplementary 143 Tables 3-4). OTUs resembling non-oomycete or non-cercozoan sequences were excluded. 144 Samples with less than 5 OTUs or with a sequencing depth lower than 20617 reads 145 (Oomycota) and 16922 reads (Cercozoa) were omitted. Statistical analyses of alpha and 146 beta diversity and final visualizations were performed in R v3.5.3 (R Core Team, 2019) with 147 the packages vegan (Oksanen et al., 2019), ggplot2 (Wickham, 2016) and ggraph 148 (Pedersen, 2020). 


\section{Results}

3.1. Amplification, sequencing and bioinformatic pipeline

151 After DNA isolation, all oomycete samples were amplified successfully whereas nine out of

15220 cercozoan samples had to be excluded due to the failure of successful amplification of 153 duplicates. Further, samples containing less than $1 \mathrm{ng} / \mu \mathrm{l}$ DNA were excluded from 154 subsequent processing, as well as samples with a low sequencing depth (see 2.3), yielding 1559 cercozoan samples from March and 4 from May, as well as 13 oomycete samples from 156 March and 20 from May (Supplementary Table 5). Of cercozoan sequences, 94.4\% could 157 be merged with a mean length of $370 \pm 35$ bp resulting in 122 OTUs in total. Of oomycete 158 sequences, $92.6 \%$ of derived 300 bp long paired-end sequences could be merged and the 159 mean fragment length accounted for $285 \pm 38 \mathrm{bp}$, which were finally clustered into 81 OTUs.

161 Neither species richness nor Shannon-diversity nor evenness of Cercozoa or Oomycota 162 differed between tree species, ground and canopy or non-arboreal controls, although 163 variation of canopy samples was much lower than of ground samples in Cercozoa (e.g. 164 species richness $\left.C V_{\text {Ground }}=42.3 \%, \mathrm{CV}_{\text {Canopy }}=5.6 \%\right)$. However, Shannon-diversity and 165 evenness of both protistan groups and species richness of oomycetes were higher in May 166 than in March, indicating that the tree foliage in May did not restrict protistan distribution 167 (Figure 1). 

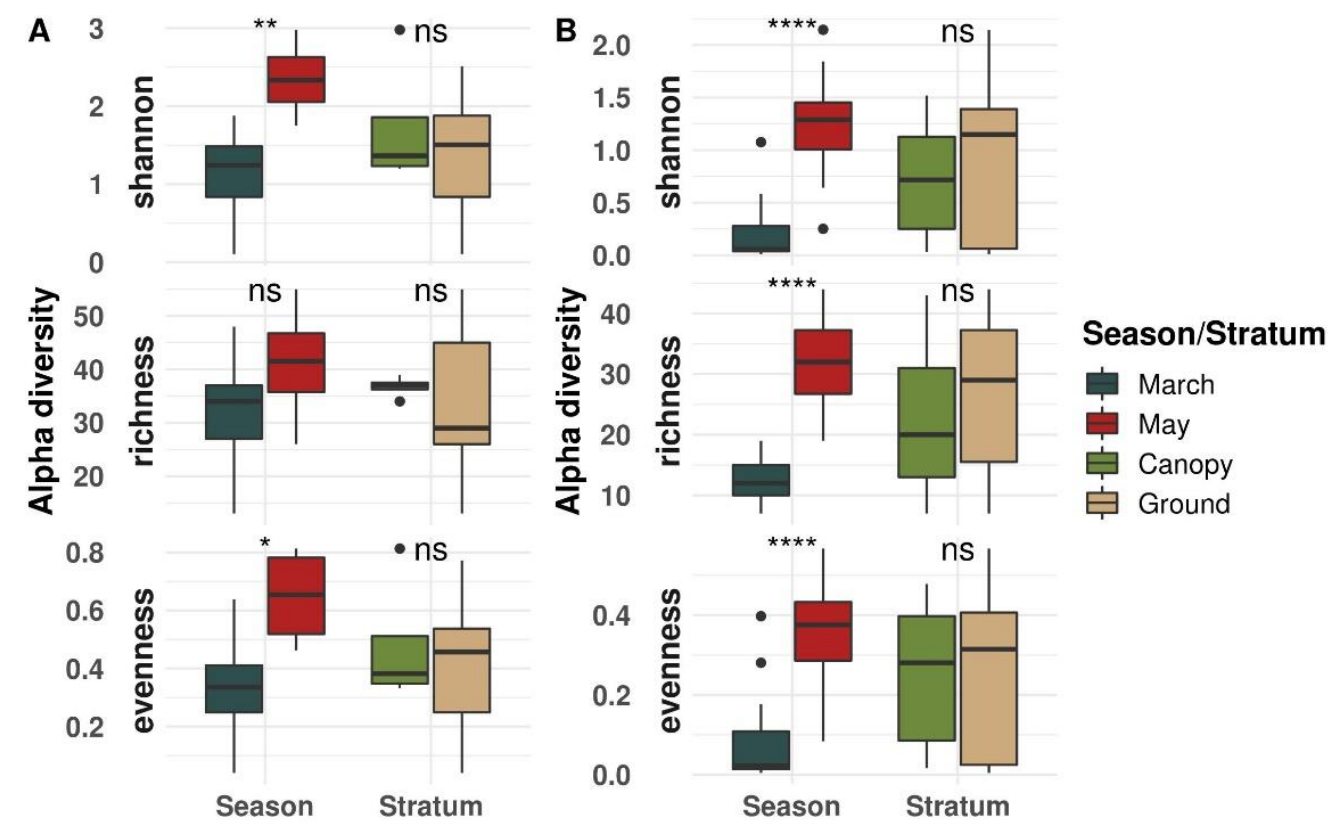

Figure 1: Boxplot of alpha diversity indices of cercozoan (A) and oomycete (B) samples. Pairwise comparisons of March and May samples and canopy and ground samples, respectively are shown. Significance was tested with Wilcoxon Sign test and is indicated by asterisks ( $n s=p>0.05$, * $p<0.05, * *=p<0.01, * * *=p<0.001, * * * *=p<0.0001)$.

\subsection{Beta diversity}

170 For Cercozoa, $\beta$-diversity of air samples did not differ between tree species (permANOVA $171 R^{2}=0.165, p=0.514$ ), ground vs. canopy stratum (permANOVA $R^{2}=0.093, p=0.296$ ) nor 172 sampling season (permANOVA $R^{2}=0.101, p=0.168$ ). However, variation of $\beta$-diversity was 173 much lower in May compared to March, and lower in canopy samples compared to ground 174 samples (Figure 2A). Oomycete communities differed between sampling seasons 175 (permANOVA $R^{2}=0.170, p=0.001$ ), but not between tree species (permANOVA $R^{2}=0.080$, $p=0.719$ ) or the strata ground and canopy (permANOVA $\left.R^{2}=0.037, p=0.259\right)$ (Figure $2 B$ ). 

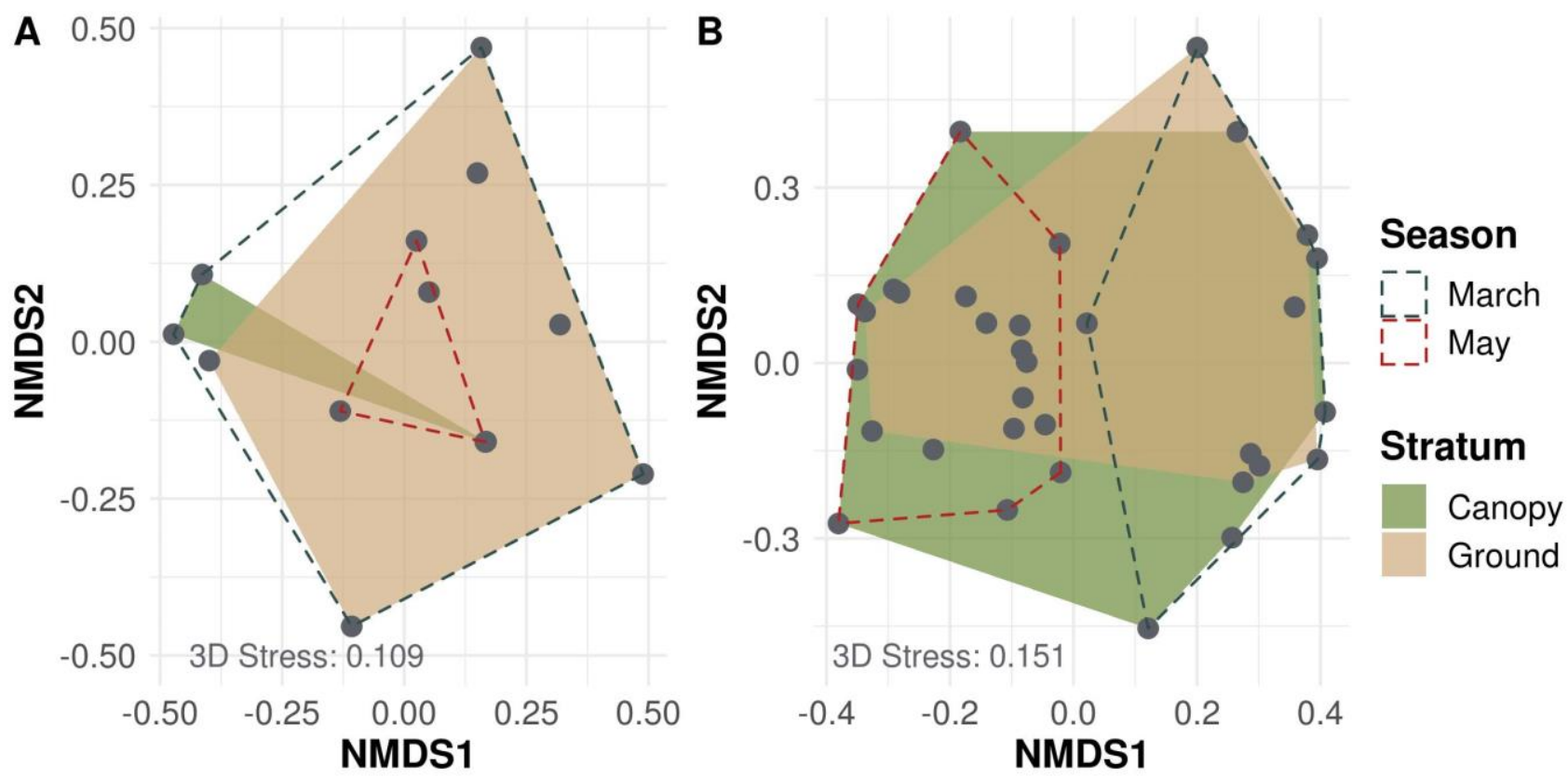

Figure 2: Non-metric multidimensional scaling (NMDS) plot of cercozoan (A) and oomycete (B) samples. Canopy and ground samples show a large overlap, while in oomycetes the March and May samples show a strong separation.

3.4. Taxonomic diversity

180 Cercozoan OTUs were dominated by the orders Cryomonadida and Glissomonadida,

181 whereas the least abundant ones were Marimonadida and an unspecified order named

182 Cercozoa_XX, comprising undescribed cercozoan lineages (Figure 3A). We detected no

183 OTUs assigned to the plant parasitic group of Endomyxa. Oomycete OTUs were almost exclusively dominated by Peronosporales (Figure 3B), with only few members of the 

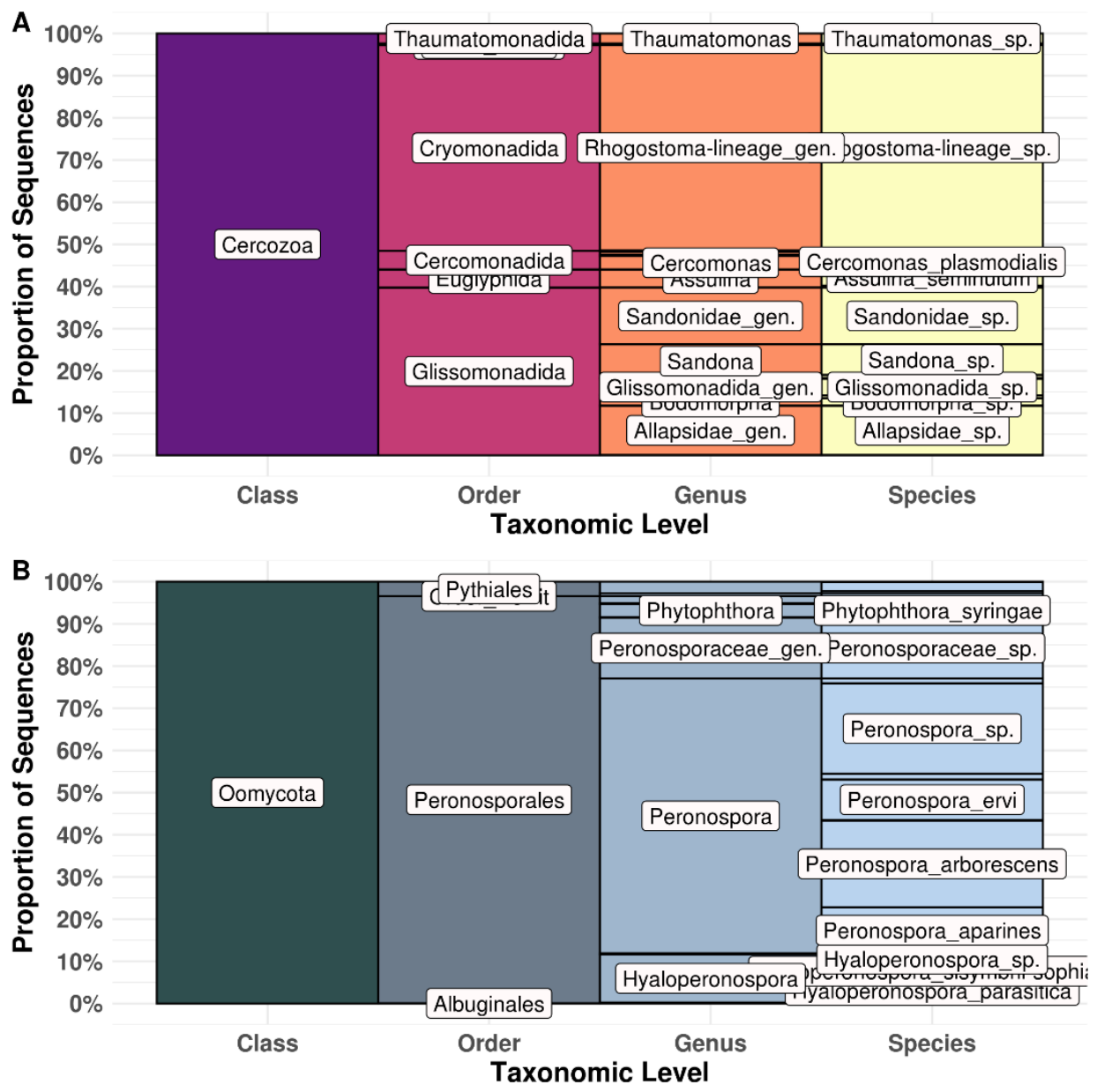

Figure 3: Taxonomic annotation of cercozoan (A) and oomycete (B) OTUs. Labels give the detected orders and the ten most abundant species with their corresponding genus.

187 The number of shared OTUs indicated a temporal variation in air dispersal of both protistan 188 taxa (Figure 4), and dispersal of cercozoan OTUs varied also spatially between canopy and 189 ground at the incidence level. 
A
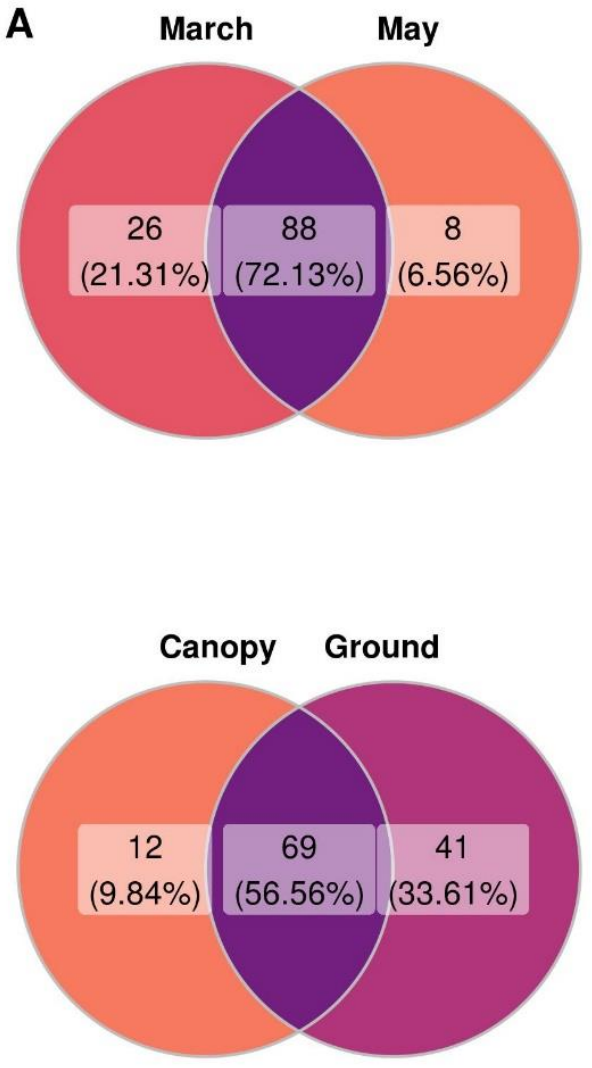

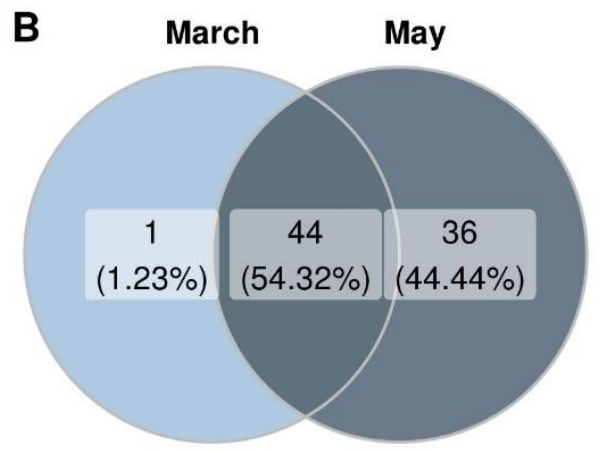

Canopy Ground

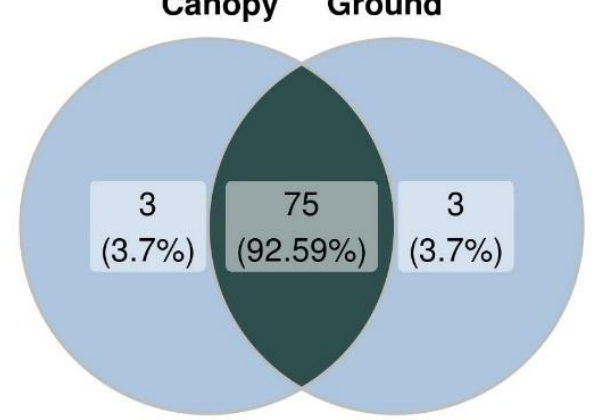

Figure 4: Venn diagram giving the number and proportion of shared OTUs between March and May samples and Canopy and Ground samples, respectively, for Cercozoa (A) and Oomycota (B).

191 Partitioning of the taxonomy into the two sampling seasons revealed similar patterns (Figure 5), yet, the cercozoan order Euglyphida was exclusively present in March samples, and oomycete Pythiales showed a higher abundance in March than in May. 


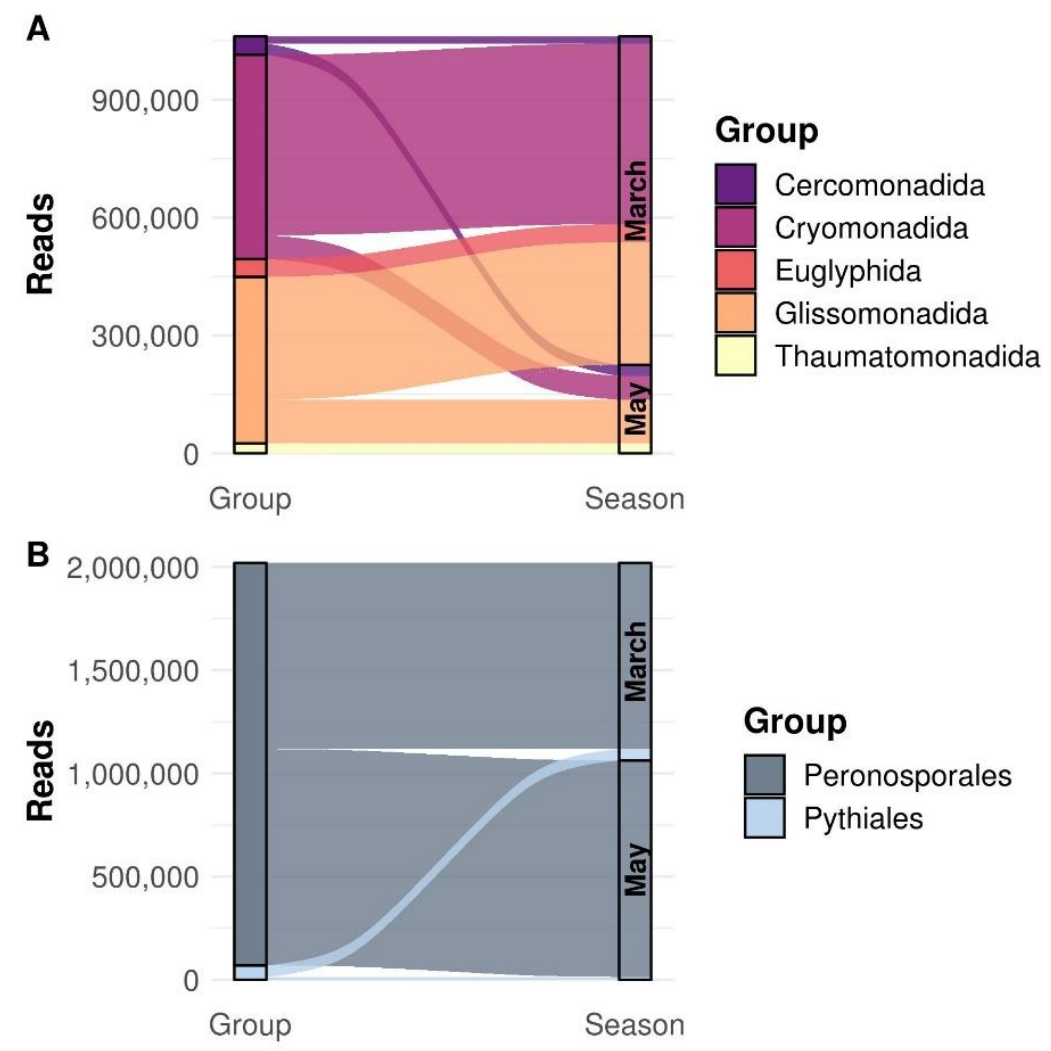

Figure 5: Sankey distribution diagram of cercozoan (A) and oomycete (B) orders in March and May samples. Orders represented by less than $1 \%$ of all reads were removed from the visualisation for the sake of clarity.

\section{Discussion}

196 In a recent study, Jauss et al. (2020) quantified the diversity of Oomycota and Cercozoa in canopy microhabitats and in litter and soil on the ground of the same floodplain forest. This

198 allows for a direct comparison of the total diversity of these protists in the forest stand with 199 the potential diversity of taxa distributed by air during two time points. We detected 122 and 81 OTUs of Cercozoa and Oomycota in air samples, respectively, which corresponds to 22 and $24 \%$ of the former reported total diversity of these protistan phyla. The high temporal variation, also reflected by the number of shared OTUs (Figure 4), suggests protistan distribution to be not restricted by dispersal-limitation, but rather indicates a continuous propagule rain of potentially invasive species and their accumulating resting stages occupying vacant niches. The vertical distribution of protists in air samples was rather homogeneous and did not differ between tree canopy and ground. In contrast, Jauss et al. 
(2020) found clear spatial patterns of oomycetes and cercozoans in tree canopies compared

208 to the forest floor, suggesting that only part of the wind-borne propagule rain finds suitable conditions for survival in tree crowns due to habitat filtering. The temporal variation could be either related to temporal variations in the activity and distribution of protists, or more likely

211 due to a dependency on the weather during the sampling. In March, the conditions were

212 less favorable, with comparatively low temperatures and humidity with immediate previous 213 precipitation events that have to be taken into account (Table 1). The remaining ground 214 moisture might have prevented the lofting of protists through wind currents, while in May the 215 atmospheric conditions were more preferable with higher average temperatures and a 216 higher humidity. The conditions in May probably favored the lofting of protists into the 217 atmosphere and their long-distance dispersal, leading to a higher protistan diversity and 218 OTU richness (Figure 1), even though the wind speed was slower compared to March (Table 219 1). As wind speed was determined to be an important factor governing the species richness 220 of microorganisms in air samples (Rogerson \& Detwiler, 1999; Genitsaris et al., 2014), faster 221 wind speeds in May probably could have revealed more protists. This suggests not a single 222 factor, but rather the interplay between atmospheric conditions driving the species richness 223 and community assembly in the air, while our samples possibly only represent the lower 224 counts of what can be dispersed by air.

225 Wind dispersal is an important means for the distribution of microbial plant pathogens, and 226 oomycetes are no exception (Fawke et al., 2015; Lang-Yona et al., 2018). Yet, 227 comprehensive assessments of their abundances within the forest air were lacking. The 228 presence of $\sim 54 \%$ of all oomycete OTUs in both sampling events (Figure $4 \mathrm{~B}$ ) indicates a 229 continuous presence of both peronosporean and pythialean oomycete spores and 230 consequently a high proportion of potentially physiologically active oomycetes, including 231 potential pathogens within forest ecosystems. Oomycetes pose a serious threat to forest 232 health and functioning, it is therefore crucial to better understand their diversity and 
233 distribution patterns of the total forest ecosystem, including air samples (Derevnina et al., 234 2016; Ajchler et al., 2017; Jung et al., 2018; Lang-Yona et al., 2018). We detected no OTUs 235 assigned to the orders Saprolegniales, Lagenidiales or Myzocytiopsidales, even though 236 Jauss et al. (2020) found them in canopy and ground samples. All three orders are capable 237 of forming dispersal stages, while their absence in our air samples could be due to a different 238 timing of their sporulation, as our samples can only represent a snapshot of aerobic diversity.

239 Three dominant cercozoan orders were detected in air samples, but surprisingly no plant 240 parasites of the Endomyxa. Testate amoebae from the orders Cryomonadida and 241 Euglyphida occurred in high numbers. Cryomonadida (Thecofilosea) are filose amoeba with 242 a robust extracellular organic tests (Adl et al., 2019). OTUs assigned to the Rhogostoma243 lineage within the Cryomonadida dominated the samples. Rhogostoma species form resting 244 stages resistant against desiccation for up to three months, although they form no cysts or 245 zoospores (Mylnikova \& Mylnikov, 2012; Öztoprak et al., 2020). Assulina seminulum, has a 246 silica test with a remarkable size of 60-90 $\mu \mathrm{m}$ (Lara et al., 2010), and dominated the air 247 dispersed Euglyphids, demonstrating that protists of this size can be still easily dispersed 248 by air (Finlay, 2002). Not surprising was the dominance of Glissomonadida, represented by 249 small flagellates of the families Sandonidae and Allapsidae. Their high abundance is 250 consistent with observations Ploch et al (2016) and Jauss et al (2020). All these orders are 251 an integral part of the protist phyllosphere microbiome (Agler et al., 2016; Dumack et al., 252 2017; Flues et al., 2018). Overall, their presence in the microbiome as well as their high 253 abundance in air samples indicates canopies and their phyllosphere to be a potential filter 254 not only for dust and particles (Weber et al., 2014; Chen et al., 2017), but also for 255 microorganisms and potential plant pathogens.

256 Conclusion

257 A significant temporal variation in oomycetes indicates protistan community and, 258 correspondingly, pathogen assembly to be driven by random factors and neutral processes, 
259 while spatial differences in the vertical distribution of cercozoans and oomycetes were not

260 found. Accordingly, wind dispersal alone may well explain the ubiquitous presence of

261 Cercozoa and Oomycota (and likely of other protistan taxa) in the floodplain forest. Our 262 results further contribute to the understanding of how protists disperse, and which factors 263 drive the distribution of plant pathogens within forest ecosystems.

\section{Acknowledgements}

265 This paper was supported by the Priority Program SPP 1991: Taxon-omics - New 266 Approaches for Discovering and Naming Biodiversity of the German Research Foundation 267 (DFG) with funding to MB (1907/19-1) and MS (Schl 229/20-1). The authors would like to 268 thank Rolf Engelmann for his assistance with the field work by operating the canopy crane, 269 and the German Centre for Integrative Biodiversity Research (iDiv) for providing the site 270 access.

\section{Conflict of Interest}

272 None declared

\section{Author Contributions}

274 MS and MB conceived the study, RW and StS designed the sampling. BS assisted the library 275 preparation. SW assisted the sampling and contributed valuably to the discussion. AN performed the sampling, laboratory work, bioinformatics analyses and outline of the manuscript. R-TJ supervised the study, sampling and bioinformatic analyses, and wrote the manuscript. All authors contributed to the manuscript and approved the final version.

\section{Data availability}

280 Raw sequence data have been submitted to the European Nucleotide Archive (ENA) 281 database under the Bioproject number PRJEB37525, with accession numbers ERS5388855 282 (Cercozoa) and ERS5388854 (Oomycota) respectively. 
bioRxiv preprint doi: https://doi.org/10.1101/2020.11.30.405688; this version posted December 2,2020 . The copyright holder for this preprint (which was not certified by peer review) is the author/funder, who has granted bioRxiv a license to display the preprint in perpetuity. It is made available under aCC-BY-NC-ND 4.0 International license.

All figures, codes and detailed bioinformatic/statistical methods used in this study are

available at https://github.com/RJauss/ToTheCanopyAndBeyond.

\section{References}

Adl, S. M., Bass, D., Lane, C. E., Lukeš, J., Schoch, C. L., Smirnov, A., Agatha, S., Berney, C., Brown, M. W., Burki, F., Cárdenas, P., Čepička, I., Chistyakova, L., del Campo, J., Dunthorn, M., Edvardsen, B., Eglit, Y., Guillou, L., Hampl, V., ... Zhang, Q. (2019). Revisions to the Classification, Nomenclature, and Diversity of Eukaryotes. Journal of Eukaryotic Microbiology, 66(1), 4-119. https://doi.org/10.1111/jeu.12691

Adl, S. M., \& Gupta, V. S. R. (2006). Protists in soil ecology and forest nutrient cycling. In Canadian Journal of Forest Research (Vol. 36, Issue 7, pp. 1805-1817). https://doi.org/10.1139/X06-056

Agler, M. T., Ruhe, J., Kroll, S., Morhenn, C., Kim, S. T., Weigel, D., \& Kemen, E. M. (2016). Microbial Hub Taxa Link Host and Abiotic Factors to Plant Microbiome Variation. PLoS Biology, 14(1), e1002352. https://doi.org/10.1371/journal.pbio. 1002352

Ajchler, M., Łobocka, M., \& Oszako, T. (2017). Pathogenic oomycetes of Phytophthora genus - a new threat to forests in Europe. Sylwan, 161(10), 870-880. https://sylwan.lasy.gov.pl/

Amato, P., Ménager, M., Sancelme, M., Laj, P., Mailhot, G., \& Delort, A.-M. (2005). Microbial population in cloud water at the Puy de Dôme: Implications for the chemistry of clouds. Atmospheric Environment, 39(22), 4143-4153. https://doi.org/10.1016/j.atmosenv.2005.04.002

Bass, D., Howe, A. T., Mylnikov, A. P., Vickerman, K., Chao, E. E., Edwards Smallbone, J., Snell, J., Cabral Jr, C., \& Cavalier-Smith, T. (2009). Phylogeny and Classification of Cercomonadida (Protozoa, Cercozoa): Cercomonas, Eocercomonas, Paracercomonas, and Cavernomonas gen. nov. Protist, 160, 483-521. https://doi.org/10.1016/j.protis.2009.01.004

Cavalier-Smith, T., Chao, E. E., \& Lewis, R. (2018). Multigene phylogeny and cell evolution of chromist infrakingdom Rhizaria: contrasting cell organisation of sister phyla Cercozoa and Retaria. Protoplasma, 255, 1517-1574. https://doi.org/10.1007/s00709-018-1241-1

Chen, L., Liu, C., Zhang, L., Zou, R., \& Zhang, Z. (2017). Variation in Tree Species Ability to Capture and Retain Airborne Fine Particulate Matter (PM2.5). Scientific Reports, 7(1), 3206. https://doi.org/10.1038/s41598-017-03360-1

Cowling, A. J. (1994). Protozoan distribution and adaptation. In J. Darbyshire (Ed.), Soil Protozoa (pp. 5-42). CAB International.

Derevnina, L., Petre, B., Kellner, R., Dagdas, Y. F., Sarowar, M. N., Giannakopoulou, A., de la Concepcion, J. C., Chaparro-Garcia, A., Pennington, H. G., van West, P., \& Kamoun, S. (2016). Emerging oomycete threats to plants and animals. In Philosophical Transactions of the Royal Society B: Biological Sciences (Vol. 371, Issue 1709). Royal Society of London. https://doi.org/10.1098/rstb.2015.0459

Dumack, K., Flues, S., Hermanns, K., \& Bonkowski, M. (2017). Rhogostomidae (Cercozoa) from soils, roots and plant leaves (Arabidopsis thaliana): Description of Rhogostoma epiphylla sp. nov. and R. cylindrica sp. nov. European Journal of Protistology, 60, 76-86. https://doi.org/10.1016/j.ejop.2017.06.001

Ellwood, M. D. F., \& Foster, W. A. (2004). Doubling the estimate of invertebrate biomass in a rainforest canopy. Nature, 429(6991), 549-551. https://doi.org/10.1038/nature02560

Evans, S. E., Dueker, M. E., Logan, J. R., \& Weathers, K. C. (2019). The biology of fog: results from coastal Maine and Namib Desert reveal common drivers of fog microbial composition. Science of The Total Environment, 647, 1547-1556. https://doi.org/10.1016/j.scitotenv.2018.08.045

Fawke, S., Doumane, M., \& Schornack, S. (2015). Oomycete Interactions with Plants: Infection Strategies and Resistance Principles. Microbiology and Molecular Biology Reviews, 79(3), 
263-280. https://doi.org/10.1128/mmbr.00010-15

Fenchel, T., \& Finlay, B. J. (2004). The Ubiquity of Small Species: Patterns of Local and Global Diversity. BioScience, 54(8), 777-784. https://doi.org/10.1641/00063568(2004)054[0777:TUOSSP]2.0.CO;2

Finlay, B. J. (2002). Global Dispersal of Free-Living Microbial Eukaryote Species. Science, 296, 1061-1063. https://doi.org/10.1126/science.1070710

Finlay, B. J., Esteban, G. F., Clarke, K. J., \& Olmo, J. L. (2001). Biodiversity of Terrestrial Protozoa Appears Homogeneous across Local and Global Spatial Scales. Protist, 152, 355-366. https://doi.org/10.1078/1434-4610-00073

Fiore-Donno, A. M., \& Bonkowski, M. (2020). Different community compositions between obligate and facultative oomycete plant parasites in a landscape-scale metabarcoding survey. Biology and Fertility of Soils. https://doi.org/10.1007/s00374-020-01519-z

Fiore-Donno, A. M., Richter-Heitmann, T., \& Bonkowski, M. (2020). Contrasting Responses of Protistan Plant Parasites and Phagotrophs to Ecosystems, Land Management and Soil Properties. Frontiers in Microbiology, 11, 1823. https://doi.org/10.3389/fmicb.2020.01823

Flues, S., Blokker, M., Dumack, K., \& Bonkowski, M. (2018). Diversity of Cercomonad Species in the Phyllosphere and Rhizosphere of Different Plant Species with a Description of Neocercomonas epiphylla (Cercozoa, Rhizaria) a Leaf-Associated Protist. Journal of Eukaryotic Microbiology, 65, 587-599. https://doi.org/10.1111/jeu.12503

Foissner, W. (2009). Protist diversity and distribution: some basic considerations. In W. Foissner \& D. L. Hawksworth (Eds.), Protist Diversity and Geographical Distribution (pp. 1-8). https://doi.org/10.1007/978-90-481-2801-3_1

Foissner, W., \& Hawksworth, D. L. (Eds.). (2009). Protist Diversity and Geographical Distribution (Vol. 8). Springer Netherlands. https://doi.org/10.1007/978-90-481-2801-3

Fuzzi, S., Mandrioli, P., \& Perfetto, A. (1997). Fog droplets - an atmospheric source of secondary biological aerosol particles. Atmospheric Environment, 31(2), 287-290. https://doi.org/10.1016/1352-2310(96)00160-4

Geisen, S., Mitchell, E. A. D., Wilkinson, D. M., Adl, S., Bonkowski, M., Brown, M. W., FioreDonno, A. M., Heger, T. J., Jassey, V. E. J., Krashevska, V., Lahr, D. J. G., Marcisz, K., Mulot, M., Payne, R., Singer, D., Anderson, O. R., Charman, D. J., Ekelund, F., Griffiths, B. S., ... Lara, E. (2017). Soil protistology rebooted: 30 fundamental questions to start with. In Soil Biology and Biochemistry (Vol. 111, pp. 94-103). https://doi.org/10.1016/j.soilbio.2017.04.001

Genitsaris, S., Kormas, K. A., Christaki, U., Monchy, S., \& Moustaka-Gouni, M. (2014). Molecular diversity reveals previously undetected air-dispersed protist colonists in a Mediterranean area. Science of the Total Environment, 478, 70-79. https://doi.org/10.1016/j.scitotenv.2014.01.071

Goheen, E. M., \& Frankel, S. J. (2009). Proceedings of the fourth meeting of the International Union of Forest Research Organizations (IUFRO) Working Party S07.02.09: Phytophthoras in forests and natural ecosystems. In Gen. Tech. Rep. PSW-GTR-221. Albany, CA: U.S. Department of Agriculture, Forest Service, Pacific Southwest Research Station. 334 p (Vol. 221). https://doi.org/10.2737/PSW-GTR-221

Guillou, L., Bachar, D., Audic, S., Bass, D., Berney, C., Bittner, L., Boutte, C., Burgaud, G., De Vargas, C., Decelle, J., Del Campo, J., Dolan, J. R., Dunthorn, M., Edvardsen, B., Holzmann, M., Kooistra, W. H. C. F., Lara, E., Le Bescot, N., Logares, R., ... Christen, R. (2013). The Protist Ribosomal Reference database (PR2): A catalog of unicellular eukaryote Small SubUnit rRNA sequences with curated taxonomy. Nucleic Acids Research, 41(D1), D597-D604. https://doi.org/10.1093/nar/gks1160

Harder, C. B., Rønn, R., Brejnrod, A., Bass, D., Al-Soud, W. A., \& Ekelund, F. (2016). Local diversity of heathland Cercozoa explored by in-depth sequencing. ISME Journal, 10(10), 2488-2497. https://doi.org/10.1038/ismej.2016.31

Jauss, R.-T., Walden, S., Fiore-Donno, A.-M., Dumack, K., Schaffer, S., Wolf, R., Schlegel, M., \& Bonkowski, M. (2020). From forest soil to the canopy: increased habitat diversity does not increase species richness of Cercozoa and Oomycota in tree canopies. Authorea Preprints. 
bioRxiv preprint doi: https://doi.org/10.1101/2020.11.30.405688; this version posted December 2, 2020. The copyright holder for this preprint (which was not certified by peer review) is the author/funder, who has granted bioRxiv a license to display the preprint in perpetuity. It is made available under aCC-BY-NC-ND 4.0 International license.

https://doi.org/10.22541/AU.158679920.02842084

Jousset, A., Lara, E., Wall, L. G., \& Valverde, C. (2006). Secondary metabolites help biocontrol strain Pseudomonas fluorescens CHA0 to escape protozoan grazing. Applied and Environmental Microbiology, 72(11), 7083-7090. https://doi.org/10.1128/AEM.00557-06 Judelson, H. S. (2017). Metabolic Diversity and Novelties in the Oomycetes. Annual Review of Microbiology, 71, 21-39. https://doi.org/10.1146/annurev-micro-090816-093609

Jung, T., Pérez-Sierra, A., Durán, A., Jung, M. H., Balci, Y., \& Scanu, B. (2018). Canker and decline diseases caused by soil- and airborne Phytophthora species in forests and woodlands. In Persoonia: Molecular Phylogeny and Evolution of Fungi (Vol. 40, pp. 182-220). Nationaal Herbarium Nederland. https://doi.org/10.3767/persoonia.2018.40.08

Kageyama, K., \& Asano, T. (2009). Life cycle of plasmodiophora brassicae. Journal of Plant Growth Regulation, 28(3), 203-211. https://doi.org/10.1007/s00344-009-9101-z

Lang-Yona, N., Pickersgill, D. A., Maurus, I., Teschner, D., Wehking, J., Thines, E., Pöschl, U., Després, V. R., \& Fröhlich-Nowoisky, J. (2018). Species Richness, rRNA Gene Abundance, and Seasonal Dynamics of Airborne Plant-Pathogenic Oomycetes. Frontiers in Microbiology, 9(NOV), 2673. https://doi.org/10.3389/fmicb.2018.02673

Lara, E., \& Belbahri, L. (2011). SSU rRNA reveals major trends in oomycete evolution. Fungal Diversity, 49, 93-100. https://doi.org/10.1007/s13225-011-0098-9

Lara, E., Heger, T. J., Scheihing, R., \& Mitchell, E. A. D. (2010). COI gene and ecological data suggest size-dependent high dispersal and low intra-specific diversity in free-living terrestrial protists (Euglyphida: Assulina): High dispersal in testate amoebae. Journal of Biogeography, 38(4), 640-650. https://doi.org/10.1111/j.1365-2699.2010.02426.x

Mahé, F., Rognes, T., Quince, C., de Vargas, C., \& Dunthorn, M. (2015). Swarm v2: highly-scalable and high-resolution amplicon clustering. PeerJ, 3, 1-12. https://doi.org/10.7717/peerj.1420

Martin, M. (2011). Cutadapt removes adapter sequences from high-throughput sequencing reads. EMBnet.Journal, 17(1), 10. https://doi.org/10.14806/ej.17.1.200

Meyer, M., \& Kircher, M. (2010). Illumina Sequencing Library Preparation for Highly Multiplexed Target Capture and Sequencing. Cold Spring Harbor Protocols, 2010(6), pdb.prot5448-pdb.prot5448. https://doi.org/10.1101/pdb.prot5448

Moon-van der Staay, S. Y., Tzeneva, V. A., Van Der Staay, G. W. M., De Vos, W. M., Smidt, H., \& Hackstein, J. H. P. (2006). Eukaryotic diversity in historical soil samples. FEMS Microbiology Ecology, 57(3), 420-428. https://doi.org/10.1111/j.1574-6941.2006.00130.x

Mylnikova, Z. M., \& Mylnikov, A. P. (2012). Structure of filose amoeba Rhogostoma minus Belar 1921 (Cryomonadida, Cercozoa) cell. Inland Water Biology, 5(3), 236-240. https://doi.org/10.1134/S1995082912020101

Oksanen, J., Blanchet, F. G., Friendly, M., Kindt, R., Legendre, P., McGlinn, D., Minchin, P. R., O’Hara, R. B., Simpson, G. L., Solymos, P., Stevens, M. H. H., Szoecs, E., \& Wagner, H. (2019). vegan: Community Ecology Package. https://cran.r-project.org/package=vegan

Ozanne, C. H. P., Anhuf, D., Boulter, S. L., Keller, H., Kitching, R. L., Körner, C., Meinzer, F. C., Mitchell, A. W., Nakashizuka, T., Silva Dias, P. L., Stork, N. E., Wright, S. J., \& Yoshimura, M. (2003). Biodiversity meets the atmosphere: A global view of forest canopies. In Science (Vol. 301, Issue 5630, pp. 183-186). American Association for the Advancement of Science. https://doi.org/10.1126/science.1084507

Öztoprak, H., Walden, S., Heger, T., Bonkowski, M., \& Dumack, K. (2020). What drives the diversity of the most abundant terrestrial cercozoan family (Rhogostomidae, cercozoa, rhizaria)? Microorganisms, 8(8), 1-16. https://doi.org/10.3390/microorganisms8081123

Pedersen, T. L. (2020). ggraph: An Implementation of Grammar of Graphics for Graphs and Networks (2.0.3). https://cran.r-project.org/package=ggraph

Pepper, I. L., \& Dowd, S. E. (2009). Aeromicrobiology. In R. M. Maier, I. L. Pepper, \& C. P. Gerba (Eds.), Environmental Microbiology (Second Edition) (Second Edi, pp. 83-102). Academic Press. https://doi.org/https://doi.org/10.1016/B978-0-12-370519-8.00005-5

Petz, W., \& Foissner, W. (1988). Spatial separation of terrestrial ciliates and testaceans (Protozoa): a 
contribution to soil ciliatostasis. Acta Protozoologica, 27(3), 249-258.

Ploch, S., Rose, L. E., Bass, D., \& Bonkowski, M. (2016). High Diversity Revealed in LeafAssociated Protists (Rhizaria: Cercozoa) of Brassicaceae. The Journal of Eukaryotic Microbiology, 63(5), 635-641. https://doi.org/10.1111/jeu.12314

R Core Team. (2019). R: A Language and Environment for Statistical Computing. https://www.rproject.org/

Robideau, G. P., De Cock, A. W. A. M., Coffey, M. D., Voglmayr, H., Brouwer, H., Bala, K., Chitty, D. W., Désaulniers, N., Eggertson, Q. A., Gachon, C. M. M., Hu, C. H., Küpper, F. C., Rintoul, T. L., Sarhan, E., Verstappen, E. C. P., Zhang, Y., Bonants, P. J. M., Ristaino, J. B., \& André Lévesque, C. (2011). DNA barcoding of oomycetes with cytochrome c oxidase subunit I and internal transcribed spacer. Molecular Ecology Resources, 11(6), 1002-1011. https://doi.org/10.1111/j.1755-0998.2011.03041.x

Rogerson, A., \& Detwiler, A. (1999). Abundance of airborne heterotrophic protists in ground level air of South Dakota. Atmospheric Research, 51, 35-44. https://doi.org/10.1016/S01698095(98)00109-4

Rognes, T., Flouri, T., Nichols, B., Quince, C., \& Mahé, F. (2016). VSEARCH: A versatile open source tool for metagenomics. PeerJ, 2016(10). https://doi.org/10.7717/peerj.2584

Thines, M. (2014). Phylogeny and evolution of plant pathogenic oomycetes-a global overview. European Journal of Plant Pathology, 138(3), 431-447. https://doi.org/10.1007/s10658-0130366-5

Urich, T., Lanzén, A., Qi, J., Huson, D. H., Schleper, C., \& Schuster, S. C. (2008). Simultaneous Assessment of Soil Microbial Community Structure and Function through Analysis of the Meta-Transcriptome. PLoS ONE, 3(6), e2527. https://doi.org/10.1371/journal.pone.0002527

Voss, C., Fiore-Donno, A. M., Guerreiro, M. A., Peršoh, D., \& Bonkowski, M. (2019). Metatranscriptomics reveals unsuspected protistan diversity in leaf litter across temperate beech forests, with Amoebozoa the dominating lineage. FEMS Microbiology Ecology, 95(10), 142. https://doi.org/10.1093/femsec/fiz142

Weber, F., Kowarik, I., \& Säumel, I. (2014). Herbaceous plants as filters: Immobilization of particulates along urban street corridors. Environmental Pollution, 186, 234-240. https://doi.org/https://doi.org/10.1016/j.envpol.2013.12.011

Wickham, H. (2016). ggplot2: Elegant Graphics for Data Analysis. Springer-Verlag New York. https://ggplot2.tidyverse.org 